\title{
Work-Related Accumulated Fatigue among Doctors in Tertiary Hospitals: A Cross-Sectional Survey in Six Provinces of China
}

\author{
Changmin Tang ${ }^{1}$, Chaojie Liu ${ }^{2, * \mathbb{D}}$, Pengqian Fang ${ }^{3, *}$, Yuanxi Xiang ${ }^{1}$ and Rui Min ${ }^{3}$ \\ 1 School of Management, Hubei University of Chinese Medicine, Wuhan 430065, China \\ 2 School of Psychology and Public Health, La Trobe University, Melbourne, VIC 3086, Australia \\ 3 Tongji Medical College, Huazhong University of Science and Technology, Wuhan 430030, China \\ * Correspondence: c.liu@latrobe.edu.au (C.L.); pfang@mails.tjmu.edu.cn (P.F.); Tel.: +613-9479-1715 (C.L.); \\ +86-13397153995 (P.F.)
}

Received: 29 July 2019; Accepted: 19 August 2019; Published: 22 August 2019

\begin{abstract}
Objectives: "Karoshi" (death due to overwork) of doctors occurred frequently and attracted increasing attention in recent years in China. This study aimed to determine the prevalence of work-related accumulated fatigue of doctors and its associated factors in tertiary hospitals of China. Methods: A cross-sectional questionnaire survey was conducted on 1729 full-time doctors employed by 24 tertiary hospitals across eastern developed, central developing, and western underdeveloped regions of China. Accumulated fatigue was categorized into four levels using the "Self-diagnosis Checklist for Assessment of Workers' Accumulated Fatigue" rated on a scale matrix considering both overwork and fatigue symptoms. Ordinal logistic regression analyses were performed to identify factors associated with work-related accumulated fatigue. Results: About $78.8 \%$ of respondents reported a "high level" of work-related accumulated fatigue, including 42.0\% at a "very high" level. Male doctors and those aged between 30 and 45 years and who had a professional title were found to have higher levels of accumulative fatigue than others. Low salary and poor working conditions (in the western region) were also significantly associated with high levels of work-related accumulated fatigue $(p<0.05)$. Conclusion: High levels of work-related accumulated fatigue are prevalent in doctors working in tertiary hospitals in China. Male doctors establishing their earlyand mid-careers are the high-risk group. Poor working conditions are associated with work-related accumulated fatigue.
\end{abstract}

Keywords: accumulated fatigue; medical doctor; tertiary hospital; work burden; China

\section{Introduction}

Overwork is often associated with high levels of accumulated fatigue, which not only affects the health and wellbeing of doctors but also jeopardizes the work performance of doctors, resulting in increased patient safety risks [1,2]. Empirical evidence shows that accumulated fatigue can accelerate thrombotic reactions [3] and even lead to sudden cardiac arrest [4]. The medical and health service industry is particularly prone to work-related accumulated fatigue due to its special nature, such as long and irregular working hours and a shortage of breaks and sleep [5-7]. Work-related accumulated fatigue was proved to be associated with burn-out of doctors [8-10]. In Japan and Korea, cerebrovascular and cardiovascular diseases (CVDs) associated with overwork have been recognized by the government for work compensation $[11,12]$.

Overwork has been reported as a silent killer of doctors in China $[13,14]$. The sudden death of three doctors from two prestigious tertiary hospitals in Beijing over a two-week period in October 2014 attracted sensational media attention [15]. Karoshi, a term that originated in Japan describing death 
due to overwork, has since become a growing occupational safety concern in the hospital sector in China $[13,14,16]$. Similar problems have also been reported in several other eastern Asian countries, including Japan and South Korea [11,13,17-19].

Hospital doctors in China bear extremely high work burdens [20]. The unprecedented economic growth in China over the past two decades has been accompanied with a dramatic increase of health care demands, particularly for hospital services. The number of hospital beds per capita (3.9 beds per 1000 people) and the hospitalization rate of residents (16\%) in China are almost on par with those of some developed countries such as Australia $[20,21]$. However, the number of hospital doctors in China lags behind at approximately $70 \%$ of the Australian level, although two-thirds of China's registered doctors (excluding assistant doctors) are employed by hospitals [20,21]. Hospital doctors in China also share a higher percentage of outpatient care than their counterparts in countries with a primary care dominated system. More than $40 \%$ of outpatient visits in China occur in hospitals, compared with less than $25 \%$ in Australia [22].

Researchers have called for increasing attention to overwork and accumulated fatigue of doctors in tertiary hospitals in China [23]. Tertiary hospitals are usually the preferred provider of medical care from consumers in China, including those with common diseases [23,24]. According to the statistics from the National Health and Family Planning Commission of China, of the 2.6 billion outpatient visits to hospitals from January to November 2014, $46 \%$ were received by tertiary hospitals [16]. It was reported that $72.43 \%$ of medical doctors employed by tertiary hospitals in China worked over 60 hours per week (Chinese Medical Doctor Association 2015) [25], way beyond the legal limit of 44 hours [26].

Extensive studies have been conducted about the role of long working hours and shift length in work-related fatigue. Sleep deprivation, physical exhaustion, and circadian rhythm disruption are considered as major contributors to work-related fatigue $[27,28]$. Work-related fatigue is also believed to be associated with many individual factors such as age, anxiety, caffeine intake, sleep patterns, and a recent life event [29].

There is a growing consensus in the literature that work-related fatigue is shaped by psychological job demands, not just quantitative physical workloads [30]. Different workers may perceive different levels of work-related fatigue for the same workloads [31]. One's perception on the workloads (e.g., ability to handle the loads) is often affected by the way the organizations value and support the work. Consumer pressure can add further stress to health workers [32]. A recent systematic literature review extracted five psychosocial variables associated with chronic fatigue: decision latitude, job stress, self-rated health, trust in management, and work-family conflict [28]. Those who have high levels of internal impetus (joy and pleasure) from work are less likely to report work-related fatigue [31]. Appropriate organizational and collegial support can often reduce or delay fatigue and improve its recovery [30].

Although work-related fatigue has attracted increasing attention in the research community, our understanding about its impacts on healthcare services is still limited. Empirical evidence is lacking regarding major harms as a result of work-related fatigue such as mortality or significant morbidity [27,33]. Most existing studies were conducted on nurses [28]. Scant literature exists regarding the influence of working environment (both physical and social) on fatigue [29]. There is also a lack of linkage between work burden and fatigue in measuring work-related fatigue.

This study aimed to determine the prevalence of work-related accumulated fatigue in medical doctors using a scale matrix that links "fatigue symptoms" and "work burden" and its associated factors in tertiary hospitals in China.

\section{Methods}

A cross-sectional questionnaire survey was conducted on doctors employed by tertiary hospitals in China. The research protocol was approved by the Ethics Committee of Tongii Medical College, Huazhong University of Science and Technology (No: IORG0003571). 


\subsection{Participants}

A multi-stage cluster sampling strategy was employed to select questionnaire respondents. Overall, the study participants were not selected randomly. However, random sampling was adopted in selecting the participating hospitals. The 31 provinces (or equivalent) in mainland China were divided into three economic zones: eastern developed (high income and social development), central developing, and western underdeveloped. At the first stage, two provinces with a middle range of socioeconomic status within each zone (Table 1) were selected: Shandong and Hebei for the east; Hubei and Henan for the central; and Qinghai and Guizhou for the west. The second stage involved a selection of two municipalities in each province: one capital and another non-capital, except for Qinghai, where tertiary hospitals are highly concentrated in the capital city. At the third stage, two tertiary hospitals in each municipality (four in the capital city of Qinghai) were identified randomly. Finally, about 80 questionnaires were dispatched to each selected hospital (a pilot survey in Hubei province indicated that a sample size of 80 medical doctors was achievable in a tertiary hospital and met the statistical power requirement for data analyses). Full-time doctors employed by these hospitals from all of the units were invited to complete the questionnaire anonymously on a voluntary basis. The questionnaire contained an information sheet explaining the purpose and the protocol of the research. Return of the completed questionnaire was deemed informed consent.

Table 1. Socioeconomic status of sampled provinces*.

\begin{tabular}{ccccccc}
\hline Socioeconomic Status & \multicolumn{2}{c}{ Eastern } & \multicolumn{2}{c}{ Central } & \multicolumn{2}{c}{ Western } \\
\cline { 2 - 7 } & Shandong & Hebei & Hubei & Henan & Qinghai & Guizhou \\
\hline Population (Million) & 100.06 & 75.20 & 59.02 & 95.59 & 5.98 & 35.80 \\
GDP per capita (Chinese Yuan) & 72,851 & 47,985 & 61,972 & 47,130 & 44,348 & 37,956 \\
(Assistant) Doctors per 1000 population & 2.6 & 2.6 & 2.5 & 2.3 & 2.6 & 2.1 \\
Facility beds per 1000 population & 5.84 & 5.25 & 6.37 & 5.85 & 6.41 & 6.51 \\
Number of tertiary hospitals & 148 & 62 & 100 & 77 & 18 & 44 \\
\hline
\end{tabular}

* Data source: National Health Commission (2018), Statistical Bulletin on the Development of Health Services in China. GDP: gross domestic product.

Data were collected from January to November 2018. A team comprising several trained research students led by one of the principal investigators visited the participating hospitals, approached the doctors on the day of their visits, invited them to complete the questionnaire independently, and collected the completed questionnaires on the sites. None of the team members had any relationship with the respondents. This resulted in a total of 1729 completed questionnaires, accounting for $90.05 \%$ of dispatched questionnaires. The sample size was large enough to enable inclusions of over 30 independent variables in the statistical modeling [34].

\subsection{Measurements}

The "Self-diagnosis Checklist for Assessment of Workers' Accumulated Fatigue" was published by the Ministry of Health, Labor and Welfare of Japan, which has been validated in a range of healthcare settings in Japan, China, and some other countries [35-37]. The translated Chinese version demonstrated good reliability and construct and discriminatory validity in various populations in China [37,38]. In this study, high internal consistence of this instrument was evident, as indicated by the Cronbach's alpha: 0.936 for "fatigue symptoms" and 0.853 for "work burdens".

The "Self-diagnosis Checklist for Assessment of Workers' Accumulated Fatigue" uses a scale matrix measuring work-related accumulated fatigue. Respondents were asked to rate their feelings over the past month. Fatigue symptoms (e.g., irritable moods, anxiety, restlessness, poor concentration, etc.) were rated with 13 items on a three-point scale: 0 (rarely), 1 (sometimes), and 3 (often). The symptom scores were then summed up and classified into four levels: I (0-4); II (5-10), III (11-20), IV (>20). This was then mapped into the work status scale comprising four levels of work burdens. The work 
status scale contained 7 items measuring overwork status as well as physical and mental burdens of both regular (e.g., day and night duties) and irregular (e.g., sudden job and business trip) work arrangements on a two- or three-point scale, with a higher score indicating inadequate or heavier burdens. This resulted in a summed score ranging from 0 to 15 , which was categorized into four levels of work burdens: A (0); B (1-2); C (3-5); and D ( $\geq 6)$. The combination of the two scales generated a score algorithm reflecting the degree of work-related accumulated fatigue (Table 2). It is generally believed that an adequate work burden should fall into the cells labeled 0 and 1 [37].

Table 2. Scale matrix concerning fatigue symptoms and work burdens.

\begin{tabular}{ccccc}
\hline \multirow{2}{*}{ Fatigue Symptoms } & \multicolumn{4}{c}{ Work Burdens } \\
\cline { 2 - 5 } & A & B & C & D \\
\hline I & 0 & 0 & 2 & 4 \\
II & 0 & 1 & 3 & 5 \\
III & 0 & 2 & 4 & 6 \\
IV & 1 & 3 & 5 & 7 \\
\hline
\end{tabular}

Independent variables associated with work-related accumulated fatigue were selected in reference to previous studies $[5,13,39]$. It has been widely accepted that work-related accumulated fatigue needs to be addressed through a systems approach that includes adequate work conditions and job assignments and a balance between work and life [6]. In line with the literature, the independent variables tested in this study covered the demographic characteristics (gender and age) of the respondents, their professional standing and job requirements (measured by qualification, professional title, and years of working experience), work conditions (monthly salary and location of hospitals), and family commitment (marital status and children). Significant regional disparities exist in China in terms of hospital infrastructure and staff welfare. The less developed regions (such as western China) usually have relatively low hospital resources despite worse population health status. Those hospitals are also poorly resourced and usually are not able to afford the same level of welfare support to their staff members as what is given to those in the more developed regions (such as eastern China) [40].

\subsection{Statistical Analysis}

Data were inputted into the EpiData Info 3.1 database and analyzed using the SPSS 19.0.

Work-related accumulated fatigue was ranked into four levels in line with the scale matrix algorithm: low (0-1), a little high (2-3), high (4-5), and very high (6-7). Pearson Chi-square tests were performed to identify independent variables that were associated with work-related accumulated fatigue. Those with a statistical significance $(p<0.05)$ were entered into an ordinal logistic regression model to test their statistical significance $(p<0.05)$ in association with work-related accumulated fatigue after controlling for variations in other independent variables.

We performed two regression analyses using two different measures for the dependent variable. The major findings reported in the manuscript used the scale matrix score as a dependent variable, which considered both "fatigue symptoms" and "work burdens". As a result, workloads and work scheduling were excluded from the modelling simply because they overlapped with "work burden" measurements in the scale matrix. In the second regression analysis (reported in the Appendix A), we singled out "fatigue symptoms" as the dependent variable, which allowed us to include workloads and work scheduling in the modeling.

\section{Results}

\subsection{Characteristics of Respondents}

About $53.7 \%$ of respondents were men and $46.3 \%$ were women. The majority $(53.7 \%)$ of respondents were aged between 30 and 45 years. Most (74.4\%) were married at the time of the survey. More than 
half $(51.0 \%)$ of the respondents had only one child, compared with $34.9 \%$ having no child and $14.1 \%$ having two or more children. A very small percentage (1.9\%) of respondents did not have a medical degree due to disruptions in their medical education during the Cultural Revolution (1966-1976). On average, respondents from the eastern hospitals had higher qualifications $\left(\chi^{2}=309.253, p<0.001\right)$ and earned a higher income $\left(\chi^{2}=40.770, p<0.001\right)$ than their central and western colleagues (Table 3 ).

Table 3. Characteristics of respondents by region.

\begin{tabular}{|c|c|c|c|c|c|}
\hline \multirow{2}{*}{ Characteristics } & \multicolumn{3}{|c|}{ Number (\%) of Respondents } & \multirow{2}{*}{$\chi^{2}$} & \multirow{2}{*}{$p$} \\
\hline & Eastern & Central & Western & & \\
\hline \multicolumn{6}{|l|}{ Gender } \\
\hline Men & $278(49.9)$ & $348(58.7)$ & $302(52.2)$ & 9.695 & 0.008 \\
\hline Women & $279(50.1)$ & $245(41.3)$ & $277(47.8)$ & & \\
\hline \multicolumn{6}{|l|}{ Age (years) } \\
\hline$<30$ & $124(22.3)$ & $153(25.8)$ & $209(36.1)$ & 33.196 & $<0.001$ \\
\hline $30-45$ & $327(58.7)$ & $315(53.1)$ & $287(49.6)$ & & \\
\hline$>45$ & 106(19.0) & $125(21.1)$ & $83(14.3)$ & & \\
\hline \multicolumn{6}{|l|}{ Marital status } \\
\hline Married & $430(77.2)$ & $442(74.5)$ & $414(71.5)$ & 4.846 & 0.089 \\
\hline Not married & $127(22.8)$ & $151(25.5)$ & $165(28.5)$ & & \\
\hline \multicolumn{6}{|l|}{ Qualification } \\
\hline Associate degree & $11(2.0)$ & $17(2.9)$ & $5(0.9)$ & 309.253 & $<0.001$ \\
\hline Bachelor degree & $123(22.1)$ & $291(49.1)$ & $399(68.9)$ & & \\
\hline Master degree & $358(64.3)$ & $277(46.7)$ & $171(29.5)$ & & \\
\hline Doctor degree & $65(11.7)$ & $8(1.3)$ & $4(0.7)$ & & \\
\hline \multicolumn{6}{|l|}{ Professional title * } \\
\hline No professional title & $60(10.8)$ & $46(7.8)$ & 61(10.5) & 33.562 & $<0.001$ \\
\hline Junior & $161(28.9)$ & $226(38.1)$ & $255(44.0)$ & & \\
\hline Middle & 208(37.3) & $191(32.2)$ & $160(27.6)$ & & \\
\hline Senior & $128(23.0)$ & $130(21.9)$ & 103(17.8) & & \\
\hline \multicolumn{6}{|l|}{ Monthly salary (yuan) } \\
\hline$<5000$ & $220(39.5)$ & $292(49.2)$ & $244(42.1)$ & 40.770 & $<0.001$ \\
\hline $5000-8000$ & $226(40.6)$ & 201(33.9) & $278(48.0)$ & & \\
\hline$>8000$ & $111(19.9)$ & $100(16.9)$ & $57(9.8)$ & & \\
\hline \multicolumn{6}{|l|}{ Years of work experience } \\
\hline$<5$ & $196(35.2)$ & $220(37.1)$ & $220(38.0)$ & 3.850 & 0.427 \\
\hline $5-10$ & $205(36.8)$ & $196(33.1)$ & $182(31.4)$ & & \\
\hline$>10$ & $156(28.0)$ & $177(29.8)$ & $177(30.6)$ & & \\
\hline \multicolumn{6}{|l|}{ Children } \\
\hline no & $176(31.6)$ & $186(31.4)$ & 241(41.6) & 19.789 & 0.001 \\
\hline 1 & $305(54.8)$ & $309(52.1)$ & $268(46.3)$ & & \\
\hline 2 or more & $76(13.6)$ & $98(16.5)$ & $70(12.1)$ & & \\
\hline
\end{tabular}

Note*: China has established a hierarchical career structure for medical doctors. A professional title is given to a practitioner considering her/his tertiary qualification, work experience, and research achievements. However, not all practicing doctors are given a professional title. Assistant doctors were not included in this study because very few existed in tertiary hospitals.

\subsection{Work-Related Accumulated Fatigue and Associated Factors}

About $21.2 \%$ of respondents reported a low level of work-related accumulated fatigue, compared with $23.4 \%$ reporting a high level and $42.0 \%$ reporting a very high level of accumulated fatigue. Men $\left(\chi^{2}=10.823, p=0.013\right)$ and those who were $30-45$ years of age $\left(\chi^{2}=26.410, p<0.001\right)$, held a professional title $\left(\chi^{2}=35.184, p<0.001\right)$, earned a lower salary $\left(\chi^{2}=28.309, p<0.001\right)$, and worked in the central/western regions $\left(\chi^{2}=31.975, p<0.001\right)$ were more likely to report higher levels of work-related accumulated fatigue (Table 4). 
Table 4. Factors associated with work-related accumulated fatigue-results of chi-square tests.

\begin{tabular}{|c|c|c|c|c|c|c|}
\hline \multirow[b]{2}{*}{ Variables } & \multicolumn{4}{|c|}{ Number (\%) of Respondents with Accumulated Fatigue } & \multirow[b]{2}{*}{$x^{2}$} & \multirow[b]{2}{*}{$p$} \\
\hline & $\begin{array}{c}\text { Low N } \\
(\%)\end{array}$ & $\begin{array}{c}\text { A little high } \mathrm{N} \\
(\%)\end{array}$ & $\underset{(\%)}{\operatorname{High} N}$ & $\begin{array}{c}\text { Very high } \\
(\%)\end{array}$ & & \\
\hline \multicolumn{7}{|l|}{ Gender } \\
\hline Men & 182(19.6) & $119(12.8)$ & $204(22.0)$ & $423(45.6)$ & \multirow{2}{*}{10.823} & \multirow{2}{*}{0.013} \\
\hline Women & $185(23.1)$ & $112(14.0)$ & $201(25.1)$ & $303(37.8)$ & & \\
\hline \multicolumn{7}{|l|}{ Age (years) } \\
\hline$<30$ & $119(24.5)$ & $75(15.4)$ & $120(24.7)$ & $172(35.4)$ & \multirow{3}{*}{26.410} & \multirow{3}{*}{$<0.001$} \\
\hline $30-45$ & $166(17.9)$ & $118(12.7)$ & $208(22.4)$ & $437(47.0)$ & & \\
\hline$>45$ & $82(26.1)$ & $38(12.1)$ & $77(24.5)$ & $117(37.3)$ & & \\
\hline \multicolumn{7}{|l|}{ Marital status } \\
\hline Married & $262(20.4)$ & $166(12.9)$ & $296(23.0)$ & $562(43.7)$ & \multirow{2}{*}{6.345} & \multirow{2}{*}{0.096} \\
\hline Single & $105(23.7)$ & $65(14.7)$ & $109(24.6)$ & $164(37.0)$ & & \\
\hline \multicolumn{7}{|l|}{ Qualification } \\
\hline $\begin{array}{c}\text { Bachelor degree or } \\
\text { below }\end{array}$ & 191(22.6) & $122(14.4)$ & 197(23.3) & 336(39.7)) & \multirow{3}{*}{6.381} & \multirow{3}{*}{0.382} \\
\hline Master degree & 157(19.5) & $100(12.4)$ & $189(23.4)$ & $360(44.7)$ & & \\
\hline Doctor degree & $19(24.7)$ & $9(11.7)$ & $19(24.7)$ & $30(39.0)$ & & \\
\hline \multicolumn{7}{|l|}{ Professional title } \\
\hline No professional title & $49(29.3)$ & $37(22.2)$ & $36(21.6)$ & $45(26.9)$ & 35.184 & $<0.001$ \\
\hline Junior title & $136(21.2)$ & $77(12.0)$ & $155(24.1)$ & $274(42.7)$ & & \\
\hline Medium title & $98(17.5)$ & $69(12.3)$ & $126(22.5)$ & $266(47.6)$ & & \\
\hline Senior title & $84(23.3)$ & $48(13.3)$ & $88(24.4)$ & $141(39.1)$ & & \\
\hline \multicolumn{7}{|l|}{$\begin{array}{l}\text { Years of work } \\
\text { experience }\end{array}$} \\
\hline$<5$ & $145(22.8)$ & $88(13.8)$ & $154(24.2)$ & $249(39.2)$ & & \\
\hline $5-10$ & 107(18.4) & $79(13.6)$ & $126(21.6)$ & $271(46.5)$ & 9.381 & 0.153 \\
\hline$>10$ & $115(22.5)$ & $64(12.5)$ & $125(24.5)$ & $206(40.4)$ & & \\
\hline \multicolumn{7}{|l|}{ Children } \\
\hline no & $134(22.2)$ & $87(14.4)$ & $147(24.4)$ & $235(39.0)$ & & \\
\hline 1 & $188(21.3)$ & $115(13.0)$ & $200(22.7)$ & $379(43.0)$ & 5.013 & 0.542 \\
\hline 2 or more & $45(18.4)$ & $29(11.9)$ & $58(23.8)$ & $112(45.9)$ & & \\
\hline \multicolumn{7}{|l|}{ Monthly salary (yuan) } \\
\hline$<5000$ & 154(20.4) & $95(12.6)$ & $172(22.8)$ & $335(44.3)$ & & \\
\hline $5000-8000$ & $129(18.3)$ & $96(13.6)$ & $169(24.0)$ & $311(44.1)$ & 28.309 & $<0.001$ \\
\hline$>8000$ & $84(31.3)$ & $40(14.9)$ & $64(23.9)$ & $80(29.9)$ & & \\
\hline \multicolumn{7}{|l|}{ Location } \\
\hline Eastern & $135(24.2)$ & $86(15.4)$ & $143(25.7)$ & 193(34.6) & 31.975 & $<0.001$ \\
\hline Central & $143(24.1)$ & $69(11.6)$ & $127(21.4)$ & $254(42.8)$ & & \\
\hline Western & $89(15.4)$ & $76(13.1)$ & $135(23.3)$ & $279(48.2)$ & & \\
\hline
\end{tabular}

The two regression models produced similar results, although age and gender became insignificant in predicting the level of fatigue symptoms without being linked to work burdens (Appendix A Table A1 and Appendix A Table A2). For simplicity of reporting, we only present the results of the ordinal logistic regression model on the "fatigue/work burden" scale matrix scores. The ordinal logistic regression model confirmed that gender, age, professional title, salary income, and hospital location were significantly associated with work-related accumulated fatigue after controlling for variations in other independent variables. The odds of male doctors having a higher level of work-related accumulated fatigue were $1.379(p<0.001)$ times those of female doctors. Those aged between 30 and 45 years were 1.487 times more likely to report a higher level of work-related accumulated fatigue than their older counterparts $(p=0.003)$. Higher levels of work-related accumulated fatigue were also confirmed in those who earned less income $(p<0.05)$, worked in the western region $(p<0.01)$, and had a professional title $(p<0.01)$ (Table 5$)$. 
Table 5. Factors associated with work-related accumulated fatigue-results of ordinal logistic regression modeling.

\begin{tabular}{|c|c|c|c|c|c|c|}
\hline \multirow{2}{*}{ Variables } & \multirow{2}{*}{$\beta$} & \multicolumn{2}{|c|}{ 95\% Confidence Interval } & \multirow{2}{*}{ Wald } & \multirow{2}{*}{ OR } & \multirow{2}{*}{$p$} \\
\hline & & Lower & Upper & & & \\
\hline \multicolumn{7}{|l|}{ Threshold * } \\
\hline (Low) & -0.887 & -1.206 & -0.568 & 29.667 & & $<0.001$ \\
\hline (A little high) & -0.184 & -0.499 & 0.132 & 1.297 & & 0.255 \\
\hline (High) & 0.829 & 0.510 & 1.147 & 26.045 & & $<0.001$ \\
\hline \multicolumn{7}{|l|}{ Gender } \\
\hline Men & 0.321 & 0.144 & 0.497 & 12.650 & 1.379 & $<0.001$ \\
\hline Women & Reference & & & & & \\
\hline \multicolumn{7}{|l|}{ Age (years) } \\
\hline$>45$ & 0.060 & -0.345 & 0.465 & 0.084 & 1.062 & 0.772 \\
\hline $30-45$ & 0.397 & 0.137 & 0.657 & 8.929 & 1.487 & 0.003 \\
\hline$<30$ & Reference & & & & & \\
\hline \multicolumn{7}{|l|}{ Professional title } \\
\hline Senior & 0.852 & 0.380 & 1.324 & 12.509 & 2.344 & $<0.001$ \\
\hline Middle & 0.799 & 0.407 & 1.190 & 15.980 & 2.223 & $<0.001$ \\
\hline Junior title & 0.574 & 0.245 & 0.903 & 11.694 & 1.775 & 0.001 \\
\hline No professional title & Reference & & & & & \\
\hline \multicolumn{7}{|l|}{ Monthly salary (Yuan) } \\
\hline$>8000$ & -0.911 & -1.206 & -0.617 & 36.767 & 0.402 & $<0.001$ \\
\hline $5000-8000$ & -0.272 & -0.485 & -0.058 & 6.232 & 0.762 & 0.013 \\
\hline$<5000$ & Reference & & & & & \\
\hline \multicolumn{7}{|l|}{ Location } \\
\hline Eastern & -0.538 & -0.758 & -0.318 & 23.005 & 0.584 & $<0.001$ \\
\hline Central & -0.377 & -0.594 & -0.160 & 11.566 & 0.686 & 0.001 \\
\hline Western & Reference & & & & & \\
\hline
\end{tabular}

* Threshold indicates where the latent variable is cut to make the four groups that we observe in our data.

\section{Discussion}

Our study demonstrated that $23.4 \%$ and $42.0 \%$ of doctors working in tertiary hospitals in mainland China experienced high and very high levels of accumulated fatigue, respectively. Such a prevalence and degree of work-related fatigue is quite high compared with the findings of studies conducted in other sectors, such as enterprise workers and lawyers [37,41,42]. However, it is consistent with the findings of several other studies on hospital medical workers in mainland China, although only fatigue symptoms were measured in those studies [43,44]. Taiwan has a different health system compared with mainland China, and about $31 \%$ of hospital workers in Taiwan reported work-related fatigue symptoms [45]. Internationally, the prevalence of work-related fatigue ranged from $7 \%$ to $45 \%$ [46].

The health industry is notorious for its high stress nature, often resulting in a prevalence of fatigue at the higher end of the spectrum. Fatigue impairs the physical and the cognitive functioning of health workers, which has been recognized as a safety risk to the workers themselves and the patients they care for $[27,29,30,47]$. Occupational injuries (such as musculoskeletal disorders and needlestick injury) and emotional distress and exhaustion, burnout, depression, as well as occupational stress-related cardiovascular diseases were often reported as being associated with overwork and fatigue [27,47-50]. The negative impact of fatigue on work performance has also been well documented in a wide range of health care arenas involving both physicians and nurses [32,51]. A study concluded that an average of longer than 40 hours weekly workloads in nurses, including voluntary paid overwork, is associated with $14 \%$ to $28 \%$ higher reported adverse events such as medication error, patient falls, and nosocomial infections [51].

The excessive workloads of medical doctors have shown little, if any, sign of relief in mainland China. Despite great efforts from the government to encourage more patients to seek medical attention from primary care facilities, consumers enjoy the freedom to choose their preferred providers [24]. There is a lack of consumer trust in primary care in general [13]. Hospitals, as consumer preferred providers, are still incentivized to service more patients for financial gains under the limited government 
budget support and fee-for-service payment arrangements [52]. This generates a strong incentive for physicians to seek profits in medical services [53]. All these factors contribute to the high patient load on hospitals, especially tertiary hospitals. At present, there is no legislation in mainland China restricting the workloads of health workers.

Work environment is an important factor associated with work-related accumulative fatigue in medical doctors. This study proved that low salary levels and a western location are independent predictors of higher levels of work-related accumulative fatigue after adjustments for variations in other factors. Overall, the total health expenditure in China is low, accounting for about $6 \%$ of gross domestic product (GDP) (compared with over 10\% in most developed countries) [54]. This led to low salaries and poor work conditions in many health facilities. Because health financing responsibilities are devolved to local governments, hospital work conditions in the underdeveloped western region are usually poorer than their richer counterparts in the eastern region [55]. By the end of 2017, the eastern urban areas had 4.3 doctors per 1000 population, compared with 3.7 in the central and 3.6 in the western areas in China [54]. Medical doctors in the western region have to work longer with a lower salary but enjoy fewer opportunities for career advancement [50]. The sharp contrast between the eastern and the western regions may add some additional psychological loads on medical workers in the western region, fueling work-related fatigue.

Studies about the role of home duties on work-related fatigue generated mixed results [28]. While some claimed that household work and a higher level of family commitment such as care for children can exacerbate fatigue [5,30], others argued that family support can aid the recovery of work-related fatigue [56]. In this study, we did not find evidence to support an association between work-life conflicts and work-related fatigue. Neither marital status nor number of children were found to be significant predictors of accumulated fatigue. However, male doctors and those aged between 30 and 45 years were found to have higher levels of work-related accumulative fatigue than others. This age group represents those who are establishing their early- and mid-careers. A study of 46 overwork-associated death cases in medical doctors in China revealed that most of the victims were male (43/46) and in the age bracket of 30-39 years [13].

A systematic approach is needed to address work-related accumulative fatigue issues in medical doctors. Interventions should not be restricted to those targeting individual work scheduling and coping strategies. Adequate job design, staff welfare, and work conditions are equally—if not more-important. Shortening work hours is the first step to reducing work-related fatigue. However, this has never been an easy task in healthcare, not only because there is a continuous shortage of workforce, but also because long working hours and long shifts are often considered necessary for health workers to be exposed to a sufficiently broad spectrum of cases for skill and competency gains [27,32]. There is a lack of empirical evidence to support scheduling interventions [27]. The fatigue-related risk in healthcare has to be addressed through better organizational management and organizational culture [32]. Unfortunately, modern medical and organizational management is founded on the culture of "commitment and diligence", often at the cost of "stress and fatigue" of employees [27]. If we are serious about "putting patient safety at the center of care", exhaustion of health workers should no longer be seen as a sign of dedication [32]. Future studies should explore the potential impacts of consumer and management pressures on the development of work-related accumulative fatigue.

\section{Limitations}

There are several limitations in this study. The study adopted a cross-sectional design. No causal relationships should be assumed. Participants of the study were selected from tertiary hospitals. The findings should not be extrapolated to primary and secondary hospitals. We used a scale matrix measuring work-related accumulated fatigue. Although it does not indicate a direct causal relationship between work burdens and fatigue, a significant association between work burdens and accumulated fatigue is evident. The coexistence of overwork and fatigue deserves serious concern. 


\section{Conclusions}

High levels of work-related accumulated fatigue are evident in medical doctors working in tertiary hospitals in mainland China, which are associated with gender, age, and work conditions. Male doctors as well as those who are in the age of 30-45 years, have a professional title, and earn a low salary are more likely to experience higher levels of work-related accumulated fatigue. There also exist regional disparities. Medical doctors working in the underdeveloped western region are more likely to experience work-related accumulated fatigue than their richer eastern and central counterparts. A systematic approach is needed to address the inequalities of work-related accumulated fatigue in medical doctors within and across organizations.

Author Contributions: C.T. coordinated data collection, performed statistical analyses, and wrote the first draft. C.L. led the articulation of research questions, interpretation of results, and writing of the manuscript. P.F., Y.X. and R.M. participated in data collection and statistical analyses. All of the authors contributed to the conceptualization of the project and writing of the manuscript.

Funding: This study was supported by the National Natural Science Foundation of China (No. 71603077).

Acknowledgments: We thank all the medical doctors who participated in the study and the research assistants who were involved in data collection.

Conflicts of Interest: The authors declare no conflict of interest.

Availability of Data and Materials: Data can be provided from the corresponding author upon reasonable requests. Some conditions may be imposed in line with the laws and regulations in China.

\section{Appendix A}

Table A1. Ordinal logistic regression modelling on accumulated fatigue with summarized work status.

\begin{tabular}{|c|c|c|c|c|c|c|}
\hline \multirow{2}{*}{ Variables } & \multirow{2}{*}{$\beta$} & \multicolumn{2}{|c|}{ 95\% Confidence Interval } & \multirow{2}{*}{ Wald } & \multirow{2}{*}{ OR } & \multirow{2}{*}{$p$} \\
\hline & & Lower & Upper & & & \\
\hline \multicolumn{7}{|l|}{ Threshold } \\
\hline (Level I) & -4.021 & -4.429 & -3.614 & 374.459 & & $<0.001$ \\
\hline (Level II) & -2.238 & -2.609 & -1.866 & 139.410 & & $<0.001$ \\
\hline (Level III) & 0.159 & -0.190 & 0.508 & 0.794 & & 0.373 \\
\hline \multicolumn{7}{|l|}{ Gender } \\
\hline Men & -0.157 & -0.339 & 0.025 & 2.868 & 0.855 & 0.090 \\
\hline Women & Reference & & & & & \\
\hline \multicolumn{7}{|l|}{ Age (years) } \\
\hline$>45$ & 0.409 & -0.009 & 0.827 & 3.680 & 1.505 & 0.055 \\
\hline $30-45$ & 0.147 & -0.120 & 0.415 & 1.162 & 1.158 & 0.281 \\
\hline$<30$ & Reference & & & & & \\
\hline \multicolumn{7}{|l|}{ Professional title } \\
\hline Senior & 0.167 & -0.322 & 0.656 & 0.450 & 1.182 & 0.502 \\
\hline Middle & 0.331 & -0.075 & 0.737 & 2.555 & 1.392 & 0.110 \\
\hline Junior & 0.077 & -0.266 & 0.420 & 0.196 & 1.080 & 0.658 \\
\hline No professional title & Reference & & & & & \\
\hline \multicolumn{7}{|l|}{ Monthly salary (Yuan) } \\
\hline$>8000$ & -0.829 & -1.136 & -0.522 & 27.948 & 0.436 & $<0.001$ \\
\hline $5000-8000$ & -0.378 & -0.596 & -0.159 & 11.499 & 0.685 & 0.001 \\
\hline$<5000$ & Reference & & & & & \\
\hline \multicolumn{7}{|l|}{ Location } \\
\hline Eastern & -0.397 & -0.622 & -0.171 & 11.866 & 0.672 & 0.001 \\
\hline Central & -0.328 & -.551 & -0.106 & 8.398 & 0.720 & 0.004 \\
\hline Western & Reference & & & & & \\
\hline \multicolumn{7}{|l|}{ Work status ${ }^{*}$} \\
\hline $\mathrm{A}$ & -3.467 & -3.785 & -3.149 & 455.376 & 0.031 & $<0.001$ \\
\hline B & -2.379 & -2.697 & -2.062 & 215.297 & 0.092 & $<0.001$ \\
\hline $\mathrm{C}$ & -1.368 & -1.600 & -1.137 & 134.137 & 0.255 & $<0.001$ \\
\hline $\mathrm{D}$ & Reference & & & & & \\
\hline
\end{tabular}

* The symptom scores of accumulated fatigue were summed up and classified into four levels: I (0-4); II (5-10), III (11-20), IV (>20); The score of work status ranges from 0 to 15: A (0); B (1-2); C (3-5); D ( $\geq 6)$. 
Table A2. Ordinal logistic regression modelling on accumulated fatigue with multiple work status measurements.

\begin{tabular}{|c|c|c|c|c|c|c|}
\hline \multirow{2}{*}{ Variables } & \multirow{2}{*}{$\beta$} & \multicolumn{2}{|c|}{ 95\% Confidence Interval } & \multirow{2}{*}{ Wald } & \multirow{2}{*}{ OR } & \multirow{2}{*}{$p$} \\
\hline & & Lower & Upper & & & \\
\hline \multicolumn{7}{|l|}{ Threshold } \\
\hline (Level I) & -5.690 & -6.271 & -5.108 & 367.871 & & $<0.001$ \\
\hline (Level II) & -3.858 & -4.412 & -3.303 & 185.985 & & $<0.001$ \\
\hline (Level III) & -1.277 & -1.800 & -0.754 & 22.940 & & $<0.001$ \\
\hline \multicolumn{7}{|l|}{ Gender } \\
\hline Men & -0.120 & -0.307 & 0.066 & 1.596 & 0.887 & 0.206 \\
\hline Women & Reference & & & & & \\
\hline \multicolumn{7}{|l|}{ Age (years) } \\
\hline$>45$ & 0.188 & -0.242 & 0.618 & 0.737 & 1.207 & 0.391 \\
\hline $30-45$ & -0.011 & -0.285 & 0.264 & 0.006 & 0.989 & 0.939 \\
\hline$<30$ & Reference & & & & & \\
\hline \multicolumn{7}{|l|}{ Professional title } \\
\hline Senior & 0.330 & -0.171 & 0.830 & 1.666 & 1.391 & 0.197 \\
\hline Middle & 0.422 & 0.005 & 0.839 & 3.930 & 1.525 & 0.047 \\
\hline Early career & 0.090 & -0.260 & 0.440 & 0.253 & 1.094 & 0.615 \\
\hline No professional title & Reference & & & & & \\
\hline \multicolumn{7}{|l|}{ Monthly salary (yuan) } \\
\hline$>8000$ & -0.799 & -1.114 & -0.483 & 24.596 & 0.450 & $<0.001$ \\
\hline $5000-8000$ & -0.365 & -0.590 & -0.140 & 10.127 & 0.694 & 0.001 \\
\hline$<5000$ & Reference & & & & & \\
\hline \multicolumn{7}{|l|}{ Location } \\
\hline Eastern & -0.435 & -0.668 & -0.203 & 13.478 & 0.647 & $<0.001$ \\
\hline Central & -0.401 & -0.630 & -0.173 & 11.857 & 0.670 & 0.001 \\
\hline Western & Reference & & & & & \\
\hline \multicolumn{7}{|l|}{ Overwork in one month } \\
\hline Less or appropriate & -0.770 & -1.160 & -0.380 & 14.948 & 0.463 & $<0.001$ \\
\hline Much & -0.686 & -0.979 & -0.394 & 21.149 & 0.504 & $<0.001$ \\
\hline Very much & Reference & & & & & \\
\hline \multicolumn{7}{|l|}{ Irregular work } \\
\hline Less & -0.206 & -0.488 & 0.075 & 2.067 & 0.814 & 0.150 \\
\hline Much & Reference & & & & & \\
\hline \multicolumn{7}{|l|}{$\begin{array}{c}\text { Burden on business } \\
\text { travel }\end{array}$} \\
\hline No or less & -0.026 & -0.301 & 0.249 & 0.035 & 0.974 & 0.851 \\
\hline Much & Reference & & & & & \\
\hline \multicolumn{7}{|l|}{$\begin{array}{c}\text { Burden on working late } \\
\text { at night }\end{array}$} \\
\hline Less or appropriate & -0.146 & -0.567 & 0.275 & 0.462 & 0.864 & 0.497 \\
\hline Much & -0.069 & -0.417 & 0.279 & 0.153 & 0.933 & 0.696 \\
\hline Very much & Reference & & & & & \\
\hline \multicolumn{7}{|l|}{ Rest time } \\
\hline Satisfied & -0.494 & -0.787 & -0.201 & 10.911 & 0.610 & 0.001 \\
\hline Dissatisfied & Reference & & & & & \\
\hline \multicolumn{7}{|l|}{ Mental burden of work } \\
\hline Little & -1.450 & -1.974 & -0.926 & 29.381 & 0.235 & $<0.001$ \\
\hline Much & -0.688 & -1.083 & -0.292 & 11.596 & 0.503 & 0.001 \\
\hline Very much & Reference & & & & & \\
\hline \multicolumn{7}{|l|}{$\begin{array}{l}\text { Physical burden of } \\
\text { work }\end{array}$} \\
\hline Little & -1.402 & -1.920 & -0.885 & 28.241 & 0.246 & $<0.001$ \\
\hline Much & -0.587 & -1.001 & -0.173 & 7.722 & 0.556 & 0.005 \\
\hline Very much & Reference & & & & & \\
\hline
\end{tabular}

* The symptom scores of accumulated fatigue were summed up and classified into four levels: I (0-4); II (5-10), III (11-20), IV (>20). 


\section{References}

1. Pfaff, H. Surgical safety and overwork. Br. J. Surg. 2004, 91, 1533-1535. [CrossRef] [PubMed]

2. Weinger, M.B.; Ancoli-Israel, S. Sleep deprivation and clinical performance. JAMA 2002, 287, 955-957. [CrossRef] [PubMed]

3. Otsui, K.; Yamamoto, J.; Inoue, N. Overwork accelerates thrombotic reaction: Implications for the pathogenesis of Karoshi. J. Thromb. Thrombolysis 2018, 45, 222-224. [CrossRef] [PubMed]

4. Wong, C.W.; Chan, Y.H.; Cheng, Y.H.; Lam, C.S. Is overwork a precipitant factor of idiopathic ventricular fibrillation? Int. J. Cardiol. 2016, 223, 218-219. [CrossRef] [PubMed]

5. Skinner, N.; Dorrian, J. A work-life perspective on sleep and fatigue-Looking beyond shift workers. Ind. Health 2015, 53, 417-426. [CrossRef] [PubMed]

6. Levenson, A. Workplace fatigue is a systems problem. Consult. Psychol. J. Pract. Res. 2017, 69, 130-142. [CrossRef]

7. Brum, M.C.; Filho, F.F.; Schnorr, C.C.; Bottega, G.B.; Rodrigues, T.C. Shift work and its association with metabolic disorders. Diabetol. Metab. Syndr. 2015, 7, 45. [CrossRef]

8. Gates, M.; Wingert, A.; Featherstone, R.; Samuels, C.; Simon, C.; Dyson, M.P. Impact of fatigue and insufficient sleep on physician and patient outcomes: A systematic review. BMJ Open 2018, 8, e021967. [CrossRef] [PubMed]

9. Kumar, S. Burnout and Doctors: Prevalence, Prevention and Intervention. Healthcare 2016, 4, 37. [CrossRef] [PubMed]

10. Shanafelt, T.D.; Boone, S.; Tan, L.; Dyrbye, L.N.; Sotile, W.; Satele, D.; West, C.P.; Sloan, J.; Oreskovich, M.R. Burnout and satisfaction with work-life balance among US physicians relative to the general US population. Arch. Intern. Med. 2012, 172, 1377-1385. [CrossRef]

11. Yamauchi, T.; Yoshikawa, T.; Takamoto, M.; Sasaki, T.; Matsumoto, S.; Kayashima, K.; Takeshima, T.; Takahashi, M. Overwork-related disorders in Japan: Recent trends and development of a national policy to promote preventive measures. Ind. Health 2017, 55, 293-302. [CrossRef] [PubMed]

12. Park, J.; Kim, Y.; Cheng, Y.; Horie, S. A comparison of the recognition of overwork-related cardiovascular disease in Japan, Korea, and Taiwan. Ind. Health 2012, 50, 17-23. [CrossRef] [PubMed]

13. Shan, H.P.; Yang, X.H.; Zhan, X.L.; Feng, C.C.; Li, Y.Q.; Guo, L.L.; Jin, H.M. Overwork is a silent killer of Chinese doctors: A review of Karoshi in China 2013-2015. Public Health 2017, 147, 98-100. [CrossRef] [PubMed]

14. Yin, R.X.; Huang, F.; Zhang, Q.H. Karoshi, a new epidemic in Chinese medical practitioners. Intensiv. Care Med. 2018, 44, 1187-1188. [CrossRef] [PubMed]

15. Tangii, W. Let "Karoshi" Go Away from Medical Doctors; Health Newspaper (China): Beijing, China, 2014; p. 5.

16. $\mathrm{Hu}, \mathrm{Y}$; Z Zhang, Z. Skilled doctors in tertiary hospitals are already overworked in China. Lancet Glob. Health 2015, 3, e737. [CrossRef]

17. Xiao, N.; Yang, B.F.; Shi, J.Z.; Yu, Y.G.; Zhang, F.; Miao, Q.; Li, D.R. Karoshi May Be a Consequence of Overwork-Related Malignant Arrhythmia. Med. Sci. Monit. 2019, 25, 357-364. [CrossRef] [PubMed]

18. Yamauchi, T.; Sasaki, T.; Yoshikawa, T.; Matsumoto, S.; Takahashi, M. Incidence of overwork-related mental disorders and suicide in Japan. Occup. Med. 2018, 68, 370-377. [CrossRef] [PubMed]

19. Targum, S.D.; Kitanaka, J. Overwork suicide in Japan: A national crisis. Innov. Clin. Neurosci. 2012, 9, 35-38. [PubMed]

20. Commission, N.H.A.F. China Health and Family Planning Statistical Yearbook 2016; Peking Union Medical College Press: Beijing, China, 2017.

21. Australian Institute of Health and Welfare. Hospital Resources 2014-2015: Australian Hospital Statistics; Australian Institute of Health and Welfare: Canberra, Australia, 2016.

22. Liu, C.; Legge, D. Challenges in China's health system reform: Lessons from other countries. Aust. J. Prim. Health 2017, 23, i-ii. [CrossRef]

23. Shen, Y.F.; Hao, X.Y.; Guo, T.K. Physician deaths from overwork should arouse greater attention in China. Int. J. Cardiol. 2018, 256, 23. [CrossRef]

24. Tang, C.; Luo, Z.; Fang, P.; Zhang, F. Do patients choose community health services (CHS) for first treatment in China? Results from a community health survey in urban areas. J. Community Health 2013, 38, 864-872. [CrossRef] [PubMed] 
25. Chinese Medical Doctor Association. Chinese Physician Practice Situation White Paper; Chinese Medical Doctor Association: Beijing, China, 2015.

26. Fu, Y.; Schwebel, D.C.; Hu, G. Physicians' Workloads in China: 1998-2016. Int. J. Environ. Res. Public Health 2018, 15, 1649. [CrossRef] [PubMed]

27. Parshuram, C.S. The impact of fatigue on patient safety. Pediatr. Clin. N. Am. 2006, 53, 1135-1153. [CrossRef] [PubMed]

28. Alahmadi, B.A.; Alharbi, M.F. Work-Related Fatigue Factors among Hospital Nurses: An Integrative Literature Review. Nurse Media J. Nurs. 2018, 8, 113-133. [CrossRef]

29. Knupp, A.M.; Patterson, E.S.; Ford, J.L.; Zurmehly, J.; Patrick, T. Associations Among Nurse Fatigue, Individual Nurse Factors, and Aspects of the Nursing Practice Environment. J. Nurs. Adm. 2018, 48, 642-648. [CrossRef]

30. Han, K.; Trinkoff, A.M.; Geiger-Brown, J. Factors associated with work-related fatigue and recovery in hospital nurses working 12-hour shifts. Workplace Health Saf. 2014, 62, 409-414. [CrossRef] [PubMed]

31. Liu, H.; Fan, J.; Fu, Y.; Liu, F. Intrinsic motivation as a mediator of the relationship between organizational support and quantitative workload and work-related fatigue. Hum. Factors Ergon. Manuf. 2018, 28, 154-162. [CrossRef]

32. Gaba, D.M.; Howard, S.K. Patient safety: Fatigue among clinicians and the safety of patients. N. Engl. J. Med. 2002, 347, 1249-1255. [CrossRef]

33. Noone, P.; Waclawski, E. Fatigue risk management systems needed in healthcare. Occup. Med. 2018, 68, 496-498. [CrossRef]

34. Bujang, M.A.; Sa'At, N.; Sidik, T.; Joo, L.C. Sample Size Guidelines for Logistic Regression from Observational Studies with Large Population: Emphasis on the Accuracy Between Statistics and Parameters Based on Real Life Clinical Data. Malays. J. Med. Sci. 2018, 25, 122-130. [CrossRef]

35. Cui, X.; Lu, X.; Hisada, A.; Fujiwara, Y.; Katoh, T. The correlation between mental health and multiple chemical sensitivity: A survey study in Japanese workers. Environ. Health Prev. Med. 2015, 20, 123-129. [CrossRef] [PubMed]

36. Tsuchiya, M.; Mori, E.; Sakajo, A.; Iwata, H.; Maehara, K.; Tamakoshi, K. Cross-sectional and longitudinal validation of a 13-item fatigue scale among Japanese postpartum mothers. Int. J. Nurs. Pract. 2016, 22 (Suppl. 1), 5-13. [CrossRef] [PubMed]

37. Huang, H.; Geng, D.; Chou, J. Accumulated fatigue measurement and overwork prevention. Hum. Resour. Dev. China 2009, 2009, 35-37+74. (In Chinese)

38. Xue, X.L.; Wang, T.F.; Yu, C.G. Estimation on the reliability and validity of the fatigue self-assessment scale. Zhongguo Zhong Xi Yi Jie He Za Zhi 2008, 28, 550-554. [PubMed]

39. Uehata, T. Long working hours and occupational stress-related cardiovascular attacks among middle-aged workers in Japan. J. Hum. Ergol. 1991, 20, 147-153.

40. Zhang, T.; Xu, Y.; Ren, J.; Sun, L.; Liu, C. Inequality in the distribution of health resources and health services in China: Hospitals versus primary care institutions. Int. J. Equity Health 2017, 16, 42. [CrossRef] [PubMed]

41. Yang, H.; Guo, X. A review of employee overwork in Europe, America and Japan. Hum. Resour. Dev. China 2009, 2009, 79-80+108. (In Chinese)

42. Wang, D. Evaluation and empirical study on overwork of laborers in China. Econ. Surv. 2011, 2011, 86-90. (In Chinese)

43. Cai, S.; Lin, H.; Hu, X.; Cai, Y.X.; Chen, K.; Cai, W.Z. High fatigue and its associations with health and work related factors among female medical personnel at 54 hospitals in Zhuhai, China. Psychol. Health Med. 2018, 23, 304-316. [CrossRef]

44. Gao, Y.; Wang, X.; Li, Q.; Guo, M.; Li, G. Relationship between chronic fatigue and psychological health of medical staff from 3A-hospital in Hainan Province. J. Zhengzhou Univ. Med. Sci. 2013, 48, 674-677.

45. Ho, J.C.; Lee, M.B.; Chen, R.Y.; Chen, C.J.; Chang, W.P.; Yeh, C.Y.; Lyu, S.Y. Work-related fatigue among medical personnel in Taiwan. J. Formos. Med. Assoc. 2013, 112, 608-615. [CrossRef] [PubMed]

46. Lewis, G.; Wessely, S. The epidemiology of fatigue: More questions than answers. J. Epidemiol. Community Health 1992, 46, 92-97. [CrossRef] [PubMed]

47. Luo, Z.; Bai, X.; Min, R.; Tang, C.; Fang, P. Factors influencing the work passion of Chinese community health service workers: An investigation in five provinces. BMC Fam. Pract. 2014, 15, 77. [CrossRef] [PubMed] 
48. Rothenberger, D.A. Physician Burnout and Well-Being: A Systematic Review and Framework for Action. Dis. Colon Rectum 2017, 60, 567-576. [CrossRef] [PubMed]

49. Stewart, N.H.; Arora, V.M. The Impact of Sleep and Circadian Disorders on Physician Burnout. Chest 2019. [CrossRef]

50. Rui, M.; Ting, C.; Pengqian, F.; Xinqiao, F. Burnout among anaesthetists in Chinese hospitals: A multicentre, cross-sectional survey in 6 provinces. J. Eval. Clin. Pract. 2016, 22, 387-394. [CrossRef] [PubMed]

51. Olds, D.M.; Clarke, S.P. The effect of work hours on adverse events and errors in health care. J. Saf. Res. 2010, 41, 153-162. [CrossRef]

52. Barber, S.L.; Borowitz, M.; Bekedam, H.; Ma, J. The hospital of the future in China: China's reform of public hospitals and trends from industrialized countries. Health Policy Plan. 2014, 29, 367-378. [CrossRef]

53. Li, H.; Yu, W. Enhancing community system in China's recent health reform: An effort to improve equity in essential health care. Health Policy 2011, 99, 167-173. [CrossRef]

54. China, M.O.H.O. Statistical Bulletin on the Development of Health Service in China: 2018; Peking Union Medical College Press: Beijing, China, 2018.

55. Pan, J.; Liu, H.; Wang, X.; Xie, H.; Delamater, P.L. Assessing the spatial accessibility of hospital care in Sichuan Province, China. Geospat. Health 2015, 10, 384. [CrossRef]

56. Winwood, P.C.; Lushington, K.; Winefield, A.H. Further development and validation of the Occupational Fatigue Exhaustion Recovery (OFER) scale. J. Occup. Environ. Med. 2006, 48, 381-389. [CrossRef] [PubMed]

(C) 2019 by the authors. Licensee MDPI, Basel, Switzerland. This article is an open access article distributed under the terms and conditions of the Creative Commons Attribution (CC BY) license (http://creativecommons.org/licenses/by/4.0/). 